\title{
The Mid-Term Outcomes of Cone Repair or Replacement of Tricuspid Valve in Patients with Ebstein's Anomaly: Our Experience
}

\author{
Prof. Mohammed Quamrul Islam Talukder, MBBS, FCPS, MD, FCVS, ${ }^{1}$ Saikat DasGupta, MBBS, MS, ${ }^{2}$ \\ Abdus Samad, MBBS, DA, ${ }^{3}$ Musfeq-Us-Saleheen Khan, MBBS, MS, ${ }^{1}$ Ziaur Rahman, MBBS, MS, ${ }^{1}$ \\ Prof. Mohammad Kabiruzzaman, MBBS, MD, ${ }^{4}$ Prof. ATM Khalilur Rahman, MBBS, DA, FCA, ${ }^{3}$ \\ Prof. Farooque Ahmed, MBBS, MS
}

${ }^{1}$ Department of Cardiac Surgery, National Heart Foundation Hospital and Research Institute, Mirpur, Dhaka-1216, Bangladesh; ${ }^{2}$ Department of Cardiac Surgery, Square Hospitals Limited, West, Panthapath, Dhaka-1205, Bangladesh; ${ }^{3}$ Department of Cardiac Anesthesia, National Heart Foundation Hospital and Research Institute, Mirpur, Dhaka-1216, Bangladesh; ${ }^{4}$ Department of Cardiology, National Heart Foundation Hospital and Research Institute, Mirpur, Dhaka-1216, Bangladesh

\section{ABSTRACT}

Background: Cone repair of the tricuspid valve (TV) is a contemporary reproducible technique for surgical reconstruction of Ebstein's anomaly. Different authorities have shown that this technique restores excellent tricuspid valve function. In Bangladesh, this technique still is unfamiliar to many. We hereby present a case series of cone repair and TV replacement with the mid-term outcome (one year to six years) at the National Heart Foundation Hospital \& Research Institute, Dhaka, Bangladesh.

Methods: We prospectively studied 21 patients, who underwent surgical intervention (cone repair or tricuspid valve replacement) for Ebstein's anomaly of TV from March 2014 to June 2020. We divided the total patient population into the cone repair and TV replacement groups. Preoperative, postoperative, and follow-up data were collected from the hospital records, telephone conversations, and hospital visits. All collected data statistically were analyzed.

Results: Our patients showed there were statistically significant improvements after surgical intervention regarding, tricuspid regurgitation (TR) $(P<0.001)$, tricuspid annular plane systolic excursion (TAPSE) $(P<0.001)$, right ventricular (RV) function $(P<0.001)$, and New York Heart Association (NYHA) class $(P<0.001)$. These developments were sustained throughout the follow-up period.

Conclusion: Cone repair should be offered to the symptomatic patients of Ebstein's anomaly because symptoms relief, reduction of morbidity, and survival benefits are excellent. Above all, the cone reconstruction shows fantastic results and may well become the surgical technique for patients with Ebstein's anomaly. We hope that new valve repair programs

Received Fuly 23, 2021; accepted December 10, 2021.

Correspondence: Saikat DasGupta, MD, Department of Cardiac Surgery, Square Hospitals Limited, West Panthapath, Dhaka-1205, Bangladesh; Telephone +8801715739487 (e-mail: saikatdasgupta@ymail.com). may provide extended longevity and restored quality of life to the patient of Ebstein's anomaly (EA) with the appropriate measures. In case of failed repair, valve replacement is an encouraging option.

\section{INTRODUCTION}

Ebstein's anomaly (EA) comprises $1 \%$ of all congenital heart diseases. Severe tricuspid regurgitation usually occurs due to right ventricular myopathy and failure of tricuspid valve delamination with greatly variable tricuspid valve morphology. The scale of abnormality in Ebstein's anomaly may vary from only minimal displacement of the septal and inferior leaflets to significant displacement with tethering [Brown 2008]. The disease is the only congenital heart lesion with a varied range of clinical expressions from a severely symptomatic neonate to an asymptomatic adult. Most patients are diagnosed in infancy or childhood, except a smaller percentage with mild malformations in adulthood. Neonates usually present with cyanosis and heart failure due to tricuspid regurgitation (TR). Children, adolescents, and adults present with exertional dyspnea, fatigue, cyanosis (sometimes just exertional), and palpitations with a few asymptomatic patients. Paradoxical embolization sometimes occurs through interatrial communication [Attenhofer 2014]. In advanced disease, hepatic and jugular venous distention can be present. The most commonly associated cardiac defects include atrial septal defect or patent foramen ovale (80-90\%), pulmonary valve stenosis or pulmonary atresia, ventricular septal defect, and patent ductus arteriosus, etc [Brown 2008; DasGupta 2020].

Surgical treatment of EA was first reported by Hunter and Lillehei in 1958 [Hunter 1958]. Symptoms of congestive heart failure, increasing cyanosis $\left(s P_{0} 2<90 \%\right)$, atrial or ventricular arrhythmias not amenable to other therapy, deteriorating systolic function, paradoxical embolization, progressive RV dilatation on echocardiography, and progressive cardiomegaly on chest X-ray (cardiothoracic ratio > 0.65) are considered indications for surgery [Saxena 2019; Brown 
2008]. Standard popular operative management of EA in neonates are biventricular repair, single ventricle repair, and heart transplantation and in the children, adolescents, and adults, treatment consists of one and a half ventricle repair, bi-ventricular repair, TV repair or replacement, selective plication of the atrialized RV, correction of any associated anomaly and rarely cardiac transplant [Silva 2019; Saxena 2019]. Multiple authorities have described numerous techniques of tricuspid valve repair in EA. But in 2004, Da Silva et al. [Da Silva 2004] introduced cone reconstruction (CR) of TV, which can attain near-normal restoration of the tricuspid valve anatomy. This repair technique is promising, in terms of early and intermediate results [Brown 2008]. In cases where repair is not possible, a valve replacement (TVR) with a biological prosthesis can be chosen. As no study has been conducted in our country among EA patients, we aimed to see the mid-term outcomes, of surgical intervention (CR or the TVR) in this cohort.

\section{METHODS}

We treated a total of 22 patients with tricuspid repair or replacement for Ebstein's anomaly at the National Heart Foundation Hospital \& Research Institute between March 2014 to June 2019. Among them, this prospective cohort study included 21 patients, and the remaining one patient was lost to follow up. All patients who underwent surgical intervention of tricuspid valve for EA (with or without concomitant other cardiac surgical procedures) in the cardiac surgery department were included in this study after fulfilling all ethical issues. After admission, all patients went through routine preoperative investigation, especially Color-Doppler echocardiography, which was critical in planning for repair or replacement the tricuspid valve. In all 21 patients, we primarily planned cone repair, but patients with inadequate valve tissue for repair or showing significant regurgitation after repair by a trans-esophageal echocardiogram (TEE) received a bio-prosthetic valve at the tricuspid position. The total patient population was divided into the cone repair and TV replacement groups.

Keeping compliance with the Helsinki declaration of medical research involving human subjects in 1964, all patients verbally were informed about the design and purpose of the study. Participants had the right to withdraw themselves from the project at any time and reason. Informed written consent was taken from the respondents. No data were disclosed without the respondents' permission; no forceful attempt was taken to interview any unwilling respondent. Permission was taken from the academic and institutional ethical and review board of the National Heart Foundation Hospital \& Research Institute for conducting this study.

Operative procedure: All patients were operated through median sternotomy under general anesthesia with a standard protocol after establishing all monitoring lines. Intraoperative TEE was performed before initiation of cardiopulmonary bypass to assess the tricuspid valve morphology, degree of tricuspid regurgitation, sub-valvular structures and to measure the RV functions and dimensions. Cardiopulmonary bypass $(\mathrm{CPB})$ was established with aortic and bi-caval venous cannulation and the left ventricle was vented through the right upper pulmonary vein. The distal ascending aorta was then clamped, and the heart was arrested with antegrade cold blood cardioplegia. The right atrium (RA) was opened, and the cone reconstruction technique was performed where possible strictly according to the description given by $\mathrm{Da}$ Silva et al. [Da Silva 2004]. This includes: 1. RAtomy margins were retracted with silk stay sutures, 2 . Pledgeted 4'0 polypropylene stay sutures were placed at the true annulus at the 10 o'clock and 2 o'clock positions and valve was tested with saline, 3 . The anterior leaflet was detached at 12 o'clock position and separated from annulus clockwise with fine scissors; all the abnormal attachments of the leaflet to the right ventricle (RV) wall were carefully detached, preserving the terminal cords (delamination). In case of deficient terminal cord, multiple fenestrations were done from terminal attachment towards base maximum up to one-third depth, 4. Posterior and septal leaflets were similarly detached from the annulus, and delamination and fenestrations were done where required, 5 . The detached terminal margin of the posterior leaflet was clockwise rotated and sutured to the detached septal margin to increase the depth of the septal margin and create a cone, 6 . The atrialized RV wall was carefully plicated longitudinally with 4'O polypropylene in double layers from apex to base towards annulus, taking special care not to entangle RCA in the sutures, 7. The true annulus was reduced to the size that matches the base of the cone with multiple pledgeted 4'O polypropylene sutures, 8 . The base of the cone of leaflets was then reattached to the neo-annulus with 5 'O polypropylene continuous sutures, 9. Thereafter reduction right atrioplasty was done and the valve was tested with saline injection into $\mathrm{RV}$, and if competent, 10. Associated surgical procedures were performed to repair the accompanied cardiac anomalies (one ventricular septal defect closure, one mitral valve replacement, one CABG), 11. ASD was then closed, most of the time directly, followed by RAtomy closure, and CPB was weaned off and once the heart started ejecting, and adequate pressure builds up, the valve was rechecked with TEE. Indications to resume $\mathrm{CPB}$ and perform additional valve repair/replacement were remaining moderate to severe tricuspid regurgitation. When TEE showed satisfactory valve functions, protamine was given, and decannulation was done. The chest was closed in layers leaving tube drains in the mediastinum. No patients in our series received a prosthetic ring, intraoperative maze procedures, or ablation for accessory conduction pathways.

Statistical analysis: We have collected the perioperative and pre-discharge data of all patients from operation records, ICU, and hospital records. Follow-up records of all 21 patients were obtained by telephone contact or hospital visits, with a mean follow-up time of $3.04 \pm 1.31$ years. We then performed the statistical analysis with the package IBM SPSS ${ }^{\circledR}$ version 22. Continuous and categorical data were expressed as mean ( $(\mathrm{SD})$ and $\mathrm{n}(\%)$, respectively. The skewness of data was checked and kurtosis test was done to see the normal distribution of data. Comparisons of characteristics between groups were made with unpaired Student's t-test, one-way 
ANOVA, where appropriate for continuous and categorical data. The $P$-value of $<0.05$ was considered statistically significant. Study endpoints were all-cause mortality and repair/ replacement-related mortality.

\section{RESULTS}

The mean age of the patients in our study was $25.42 \pm$ 13.88 years (ranging from 12-61 years), whereas six patients were within the 15 years age group and three patients were above 50 years of age. Eight (38\%) of our patients were male, and $13(62 \%)$ patients were female. Along with tricuspid valve anomaly, $19(90.47 \%)$ of our patients had ASD or PFO, one $(4.76 \%)$ had associated VSD, and one (4.76\%) patient had associated triple vessel coronary artery disease. The mean height of our patients' was $154.29 \pm 10.88 \mathrm{~cm}$ (range 140-172 $\mathrm{cm})$, and the mean weight was $52.34 \pm 10.24 \mathrm{~kg}$ (range $28-69$ $\mathrm{kg}$ ). Mean BMI among our patients was $22.06 \pm 4.25 \mathrm{~kg} / \mathrm{m}^{2}$ (range $12.96-30.08 \mathrm{~kg} / \mathrm{m}^{2}$ ), and mean BSA was $1.48 \pm 0.18 \mathrm{~m}^{2}$.

Mean CPB time among the total study population was $197.95 \pm 55.21$ minutes, and (aortic cross clamp) ACC time was $163.05 \pm 52.68$ minutes. When compared between the cone repair $(N=12)$ and tricuspid valve replacement $(N=$ 9) groups, mean $\mathrm{CPB}$ time was $215.33 \pm 49.26$ minutes in the repair group and $174.78 \pm 56.81$ minutes in the replacement group, which was statistically not significant $(P=0.095)$. ACC time between the repair group (172.5 \pm 52.02 minutes $)$ and the replacement group $(150.44 \pm 53.88$ minutes $)$ also was not statistically significant $(P=0.355)$. Mechanical ventilation time was $12 \pm 4.42$ hours in the total study population. It was less in the cone repair group (10.92 \pm 3.61 hours) than the valve replacement group $(13.44 \pm 5.18$ hours $)$, and it was not statistically significant $(P=0.202)$. Overall ICU stays among the total population were $3 \pm 2.21$ days, which was $2.17 \pm 1.19$ days in the repair group and $4.11 \pm 2.80$ days in the replacement group, which was statistically significant $(P$ $=0.043$ ). Again, overall hospital stays were $11.95 \pm 7.39$ days. In the repair group, hospital stay was $9.08 \pm 3.94$ days and in the replacement group, it was $15.78 \pm 9.23$ days, which was statistically significant $(P=0.036)$. The TR among the total study population improved significantly $(P<0.001)$ from preoperative $3 \pm 1.23$ to post-op $0.58 \pm 0.60$, and at follow up, it was $1.10 \pm .044$. In between groups, postoperative TR was statistically significant $(P<0.001)$. Pre-op RVEF 37.14 $\pm 8.60 \%$ improved to $47.38 \pm 7.18 \%$ and follow-up RVEF was $48.81 \pm 2.7 \%$; this was statistically significant $(P<0.001)$. Nevertheless, in between groups, there was no significant difference, in terms of RVEF. Preoperative TAPSE was $9.71 \pm$ $2.17 \mathrm{~mm}$, which was postoperatively $13.52 \pm 3.68 \mathrm{~mm}$, and at follow up, it was $14.52 \pm 3.42 \mathrm{~mm}$; this was statistically significant $(\mathrm{P}<0.001)$. Preoperative, postoperative, and follow-up TAPSE was almost equal among the groups, and it was not statistically significant. Overall, NYHA class improved from pre-op $3.05 \pm 0.59$ to post-op $1.86 \pm 0.66$, and at follow up, it was $1.33 \pm 0.48$, which was statistically significant $(P<0.001)$. Again, NYHA class was almost equal in both groups, and it was not statistically significant.

\section{DISCUSSION}

In March 2014, a cone repair program was introduced at National Heart Foundation Hospital and Research Institute as part of the valve repair program. It consisted of one surgeon trained at the Mayo Clinic under cone repair program and some dedicated local surgeons, cardiologists, intensivists, and

Table 1. Demographic variables

\begin{tabular}{lc}
\hline Variables & Mean $\pm \mathrm{SD}(\mathrm{N}=21)$ \\
\hline Age (years) during surgery & $25.43 \pm 13.88$ \\
Sex & \\
Male & $8(38.1 \%)^{*}$ \\
Female & $13(61.9 \%)^{*}$ \\
Height $(\mathrm{cm})$ & $154.29 \pm 10.88$ \\
Weight $(\mathrm{kg})$ & $52.34 \pm 10.24$ \\
BMI $\left(\mathrm{kg} / \mathrm{m}^{2}\right)$ & $22.06 \pm 4.25$ \\
BSA $\left(\mathrm{m}^{2}\right)$ & $1.48 \pm 0.18$ \\
\hline
\end{tabular}

BMI, body mass index; BSA, body surface area. *denotes percentages

Table 2. Preoperative and immediate postoperative variables

\begin{tabular}{lccc}
\hline Variables & Total patients* $(N=21)$ & Cone repair* $(N=12)$ & TV replacement* $(N=9)$ \\
\hline CPB time (min) & $197.95 \pm 55.21$ & $215.33 \pm 49.26$ & $174.78 \pm 56.81$ \\
ACC time (min) & $163.05 \pm 52.68$ & $172.5 \pm 52.02$ & $150.44 \pm 53.88$ \\
Ventilation time (hours) & $12 \pm 4.42$ & $10.92 \pm 3.61$ & $13.44 \pm 5.18$ \\
ICU stay (days) & $3 \pm 2.21$ & $2.17 \pm 1.19$ & $4.11 \pm 2.80$ \\
Hospital stay (days) & $11.95 \pm 7.39$ & $9.08 \pm 3.94$ & $15.78 \pm 9.23$ \\
\hline
\end{tabular}

*Data are mean \pm standard deviation. CPB, cardio-pulmonary bypass; ACC, aortic cross clamp; ICU, intensive care unit 
anesthesiologists. The goal of the program was to increase awareness among patients and physicians about diagnosis of Ebstein's anomaly, suitable treatment, and importantly mandatory follow up. The team set up a follow-up protocol after acceptable cone repair or TV replacement, which was 1,3 , and 6 months after surgery and yearly follow up thereafter by color Doppler echocardiogram. So far, we have operated on 22 patients, and 21 patients completed at least one-year follow up under our protocol, and a good number of patients are waiting for surgery in our program.

For proper planning of possible valve repair or replacement, color Doppler echocardiography and TEE are necessary. Color Doppler echocardiography provides the best estimation of displacement of TV cusps, degree of tricuspid regurgitation, RV dimension, and both ventricular function along with associated anomaly. For better visualization of the posterior leaflet of the TV and better quantitative assessment of the right ventricular size and function, cardiac MRI helps compared to echocardiography. Cardiac MRI, when combined with echocardiography, may help in better risk stratification [Attenhofer 2011]. In our country, cardiac MRI is still not a very popular modality, due to its beyond affordability and it is only limited to one or two super-specialized diagnostic laboratories, and so we had to skip cardiac MRI in our study. We had excellent TEE support by our eminent cardiologists and anesthesiologists, who guided us throughout the operative process.

In patients with Ebstein's anomaly, cardiomegaly and impaired RV function are the main concerns and affect morbidity and mortality after repair [Badiu 2010]. The immediate postoperative phase after the cone repair is considered a critical period, beginning with weaning from the heart-lung machine. As the tricuspid valve becomes competent, the regurgitation volume, RV stroke volume, and RV ejection fraction decrease; therefore, the risk for RV failure is high, which brings out the importance of early RV unloading. A cavopulmonary anastomosis is used by most groups when facing RV failure after surgery for Ebstein's anomaly [Liu J 2011; Malhotra 2009; Chauvaud 2006]. As a bridge, temporary ECMO support may be used, and the decision for a cavopulmonary connection can be deferred. This approach was based on the assumption that RV failure is temporary. However, we never needed ECMO support in our series. We used intravenous Dobutamine, Milrinone, and low dose Adrenaline, during weaning from CPB and days afterward in ICU. Attenhofer et al. [Attenhofer 2014] showed that postoperative RV failure often could be avoided by leaving a limited residual atrial communication. This communication at follow up had no adverse effect at rest, but some concerning rightto-left shunt was observed during exercise, leading to relevant desaturation. Therefore, some of their patients needed an interventional closure of the communication. The risk of paradoxical embolization should be considered in these patients [Attenhofer 2014]. However, in our series, in every single case, we closed all abnormal shunts during primary surgery without critical consequences.

Cone repair restores the RV geometry and function as well as eliminates TR, without a prosthetic ring, and enables
Table 3. Comparison of pre, postoperative and variables among the total study population*

\begin{tabular}{lcccc}
\hline Variables & Preoperative* & Postoperative* & Follow up* & $P$ \\
\hline NYHA & $3.05 \pm 0.59$ & $1.86 \pm 0.66$ & $1.33 \pm 0.48$ & $<0.01$ \\
TR & $3 \pm 1.23$ & 0.577350269 & $1.095 \pm 0.437$ & $<0.01$ \\
RVEF & $37.14 \pm 8.598$ & $47.381 \pm 7.18$ & $48.81 \pm 2.7$ & $<0.01$ \\
TAPSE & $9.71 \pm 2.17$ & $13.52 \pm 3.68$ & $14.52 \pm 3.42$ & $<0.01$ \\
\hline
\end{tabular}

*Data are mean \pm standard deviation. NYHA, New York Heart Association; TR, tricuspid regurgitation; RVEF, right ventricular ejection fraction; TAPSE, tricuspid annular plane systolic excursion. $\mathrm{P}$ value $<0.05$ is significant.

growth of the tricuspid annulus [Li 2016]. In long-term follow up in all cases of TV repair, authorities [Silva 2019] observed good RV function and low incidence of severe TR. In a recent study of 235 patients by the Mayo Clinic group, cone repair proved to be safe and effective, with a reduction in TR and changes in RV remodeling [Holst 2017]. Encouraging outcomes were reported by other studies performing cone repair [Liu 2011; Lange 2015]. Beroukhim et al. [Beroukhim 2018] also reported improvements in RV volume and TR, besides improvement in left ventricular systolic function and synchrony in patients who underwent cone repair [Goleski 2014]. In our study, in both the cone repair and replacement groups, tricuspid regurgitation improved significantly after the surgery and the change sustained at follow up. One patient in each group developed moderate regurgitation, although they were clinically asymptomatic. As the TR grade improved, the NYHA class also reduced to I/II in most of our patients except two patients (one in each group) during the postoperative period. However, at follow up (after 1 year or more), all patients were at NYHA class I/II.

Tricuspid annular plane systolic excursion (TAPSE) is a simple, easy and reproducible parameter for quantitative assessment of the RVEF by echocardiogram [Kaul 1984]. TAPSE has well-described prognostic importance in the evaluation of RV function in patients with severe heart failure [Ghio 2000], and it has been recommended in the guidelines for echocardiographic quantification of RV function [Lang 2005]. In our series, most of our patients had a preoperative TAPSE of $<10 \mathrm{~mm}$, which improved significantly $(P<0.001)$ at follow up.

Badiu et al. showed that early timing of intervention in Ebstein's anomaly may be crucial for the surgical results [Badiu 2010]; although, Attenhofer et al. [Attenhofer 2012] found no anatomical contraindication for this technique (cone repair) in older patients. While other centers favor bio-prosthetic replacement in older patients [Attenhofer 2012], they [Attenhofer 2012] thought that repair still can be performed if RV function does not severely deteriorate. We feel that the 61-year-old patient who died in our study despite perfect valve performance may have been too old for the procedure and developed acute kidney injury and low output syndrome on the first postoperative day and died 
Table 4. Preoperative, postoperative and follow-up variables comparing Cone repair and TV replacement

\begin{tabular}{|c|c|c|c|}
\hline \multicolumn{4}{|l|}{ NYHA } \\
\hline Postoperative & $1.92 \pm 0.67$ & $1.78 \pm 0.67$ & 0.355 \\
\hline Follow up & $1.42 \pm 0.52$ & $1.22 \pm 0.44$ & 0.202 \\
\hline Preoperative & $2.92 \pm 1.38$ & $3.11 \pm 1.05$ & 0.729 \\
\hline Postoperative & $0.92 \pm 0.52$ & 0 & $<0.001$ \\
\hline Follow up & $1.08 \pm 0.29$ & $1.11 \pm 0.60$ & 0.890 \\
\hline \multicolumn{4}{|l|}{ RVEF } \\
\hline Preoperative & $37.5 \pm 9.42$ & $36.67 \pm 7.91$ & 0.832 \\
\hline \multicolumn{4}{|l|}{ TAPSE } \\
\hline Preoperative & $9.75 \pm 2.53$ & $9.67 \pm 1.732$ & 0.933 \\
\hline Postoperative & $13.33 \pm 3.68$ & $13.78 \pm 3.9$ & 0.792 \\
\hline Follow up & $14.25 \pm 3.22$ & $14.89 \pm 3.82$ & 0.683 \\
\hline
\end{tabular}

*Data are mean \pm standard deviation. NYHA, New York Heart Association; TR, tricuspid regurgitation; RVEF, right ventricular ejection fraction; TAPSE, tricuspid annular plane systolic excursion. $\mathrm{P}$ value $<0.05$ is significant.

on the second postoperative day. However, With the addition of a BDG and a TV repair or replacement [Raju 2014], low LVEF patients (as 30\%) with older age can be salvaged. With time, some of these patients show an improvement in their LV function. RV end-diastolic index $>200 \mathrm{~mL} / \mathrm{m}^{2}$, RVEF $<40 \%$, and age $>50$ years are increased risk factors for post-op RV failure. This suggests that an early intervention in EA may be beneficial and may avoid the need for a heart transplant [Mrad 2019]. When the LV function is severely depressed, some authorities suggest considering heart transplantation. In our cohort, all patients had a LVEF $>55 \%$. Although pre-op RVEF was $<40 \%$ in most of our cases, it grossly improved $(P<0.001)$ during the postoperative period and remained static at follow up.

Every attempt should be made to repair the valve, especially in younger patients, particularly in infants and young children where valve replacement options are limited. Tricuspid valve replacement is necessary when a repair is not feasible, or repair has failed. A replacement in elderly, frail patients is served better than a complex repair with prolonged operative time. It should be noted that a good replacement is better than a poor tricuspid valve repair. Between 1972 to 2006, the Mayo Clinic performed 519 operations for Ebstein's anomaly, among which 182 were repairs and 337 replacements [Brown 2008]. A valve replacement had neither impact on the survival or functional outcome of those patients, nor was there statistically significant risk of reoperation. Due to the increased thrombogenicity of the mechanical valves, which is further increased with poor RV function, a bio-prosthetic valve is better suited in the tricuspid position [Said 2014]. In case of disruption of bio-prosthesis, a percutaneous TV valve in valve replacement is a future option and can be performed with low risk [Taggart 2018].

In our series, the ICU stays and hospital stays were more in the replacement group. It was because two of our valve replacement patients needed 61 days' hospital stay (one needed 35 days and the other one needed 26 days). The one who needed 26 days also needed a permanent pacemaker for complete heart block. And again, as expected, the ACC and $\mathrm{CPB}$ time was more in the repair group than in the replacement group, although it was statistically not significant. Although genetic factors in Ebstein's anomalies are heterogeneous and familial Ebstein's is usually rare, most cases are sporadic [Postma 2011; Benson 1999; Dearani 2015]. In this context, genetic testing in this subset of patients is justified, but our patients refused to do genetic testing as it was expensive and time-consuming. We had only one mortality in the repair group and no mortality in the replacement group. No patient in our study group needed re-operation for postoperative bleeding or tamponade. One of our patients needed a permanent pacemaker in the replacement group, and none needed any re-intervention until the follow-up date. Usually in-hospital mortality is similar for TV repair and TVR [Erin 2018] but in our series we observed 1 death in repair group as we described earlier. We found no significant difference in between repair or replacement, in terms of TR, RV function improvements, and NYHA class in our series.

Limitations: This study was conducted over a smaller group of patients. There were no infants and neonates in the 
cohort. A larger sample multicenter study could provide us a better overview of the outcome of the surgery in our population. Today, there are many different forms of modalities to evaluate the right ventricular function like cardiac MRI, but this investigation is very expensive and only available in limited centers, so we could not avail those in our study. The follow-up time also is not that long, and the long-term durability and changes remain to be determined.

\section{CONCLUSION}

Ebstein's anomaly in symptomatic patients, if untreated, carries high morbidity and mortality. While arrhythmias predominate in younger age groups, stroke is frequent in the adult population with EA without a clear correlation with cardiac rhythm. Cone repair should be the first choice in suitable valve morphology, but the learning curve is significant. The development of repair techniques has not been as rapid as one would expect, but assisted by advances in TEE and superior anesthesiologist support in dedicated centers, the last few years have seen some remarkable changes. In earlier days, valve repair surgery had only been the strength of a few exceptionally gifted surgeons, but currently, cone repair can safely be done by a dedicated cone repair program like ours with a satisfactory outcome. Moreover, in case of failed repair, tricuspid valve replacement with bioprosthesis is an advantageous option.

\section{ACKNOWLEDGEMENT}

The authors would like to acknowledge Dr. Mainul Hossain Shobel, Medical Officer, Cardiac Surgery, for his relentless effort at data collection and compiling and Dr. M A Mazed Khan, Associate Professor, Department of Cardiology, and Dr. Reazul Islam, Consultant, Cardiac ICU, for their constant TEE support.

\section{REFERENCES}

Attenhofer Jost CH, Connolly HM, Scott CG, Burkhart HM, Ammash NM, Dearani JA. 2014. Increased risk of possible paradoxical embolic events in adults with Ebstein anomaly and severe tricuspid regurgitation. Congenit Heart Dis. 9:30-7.

Attenhofer Jost CH, Connolly HM, Scott CG, Burkhart HM, Warnes CA, Dearani JA. 2012. Outcome of cardiac surgery in patients 50 years of age or older with Ebstein anomaly: survival and functional improvement. J Am Coll Cardiol. 59:2101-6.

Attenhofer Jost CH, Edmister WD, Julsrud PR, et al. 2012. Prospective comparison of echocardiography versus cardiac magnetic resonance imaging in patients with Ebstein's anomaly. Int J Cardiovasc Imaging. 28:1147-59.

Badiu CC, Schreiber C, Hörer J, et al. 2010. Early timing of surgical intervention in patients with Ebstein's anomaly predicts superior longterm outcome. Eur J Cardiothorac Surg. 37(1):186-192.

Benson DW, Silberbach GM, Kavanaugh-McHugh A, et al. 1999.
Mutations in the cardiac transcription factor NKX2.5 affect diverse cardiac developmental pathways. J Clin Invest. 104(11):1567-1573.

Beroukhim RS, Jing L, Harrild DM, Fornwalt BK, Mejia-Spiegeler A, Rhodes J, et al. 2018. Impact of the cone operation on left ventricular size, function, and dyssynchrony in Ebstein anomaly: a cardiovascular magnetic resonance study. J Cardiovasc Magn Reson. 20(1):32.

Brown ML, Dearani JA, Danielson GK, et al. 2008. The outcomes of operations for 539 patients with Ebstein anomaly. J Thorac Cardiovasc Surg. 135(5):1120-1136.e11367.

Chauvaud SM, Hernigou AC, Mousseaux ER, Sidi D, Hebert JL. 2006. Ventricular volumes in Ebstein's anomaly: X-ray multislice computed tomography before and after repair. Ann Thorac Surg. 81:1443-9.

Das Gupta S, Uddin M, Howlader SS, Kumar Biswas P, Kabiruzzaman M, Islam Talukder MQ. 2020. Surgical management for an adult, female patient, with Ebstein Anomaly on Tricuspid Valve that has Subvalvular membrane with severe PS and multiple VSDs-A case report. Heart Surg Forum. 23(6):E781-E785.

Dearani JA, Mora BN, Nelson TJ, Haile DT, O'Leary PW. 2015. Ebstein anomaly review: what's now, what's next? Expert Rev Cardiovasc Ther. 13(10):1101-1109.

Erin Fender, Chad J. Zack, Alexander Egbe. 2018. National trends and outcomes for surgical treatment of Ebstein's anomaly. Mayo Clinic J Am Coll Cardiol. Mar, 71 (11 Supplement) A618.

Ghio S, Recusani F, Klersy C, et al. 2000. Prognostic usefulness of the tricuspid annular plane systolic excursion in patients with congestive heart failure secondary to idiopathic or ischemic dilated cardiomyopathy. Am J Cardiol. 85:837-42.

Goleski PJ, Sheehan FH, Chen SS, Kilner PJ, Gatzoulis MA. 2014. The shape and function of the left ventricle in Ebstein's anomaly. Int J Cardiol. 171(3):404-12.

Holst KA, Dearani JA, Said S, Pike RB, Connolly HM, Cannon BC, et al. 2018. Improving results of surgery for Ebstein anomaly: where are we after 235 cone repairs? Ann Thorac Surg. 105(1):160-8.

Hunter SW, Lillehei CW. 1958. Ebstein malformation of the tricuspid valve. Study of a case together with suggestions of a new form of surgical therapy. Dis Chest. 33(3):297-304.

Kaul S, Tei C, Hopkins JM, et al. 1984. Assessment of right ventricular function using two-dimensional echocardiography. Am Heart J. 107:526-31.

Lang RM, Bierig M, Devereux RB, et al. 2005. Recommendations for chamber quantification: a report from the American Society of Echocardiography's Guidelines and Standards Committee and the Chamber Quantification Writing Group, developed in conjunction with the European Association of Echocardiography, a branch of the European Society of Cardiology. J Am Soc Echocardiogr. 18:1440-63.

Lange R, Burri M, Eschenbach LK, Badiu CC, da Silva JP, Nagdyman N, et al. 2015. Da Silva's cone repair for Ebstein's anomaly: effect on right ventricular size and function. Eur J Cardiothorac Surg. 48(2):31621; discussion 320-1.

Li X, Wang SM, Schreiber C, Cheng W, Lin K, Sun JY, et al. 2016. More than valve repair: effect of cone reconstruction on right ventricular geometry and function in patients with Ebstein anomaly. Int J Cardiol. 206:131-7.

Liu J, Qiu L, Zhu Z, Chen H, Hong H. 2011. Cone reconstruction of the tricuspid valve in Ebstein anomaly with or without one and a half ventricle repair. J Thorac Cardiovasc Surg. 141(5):1178-83. 
Malhotra SP, Petrossian E, Reddy VM, Qiu M, Maeda K, Suleman S, et al. 2009. Selective right ventricular unloading and novel technical concepts in Ebstein's anomaly. Ann Thorac Surg. 88:1975-81.

Mrad Agua K, Burri M, Cleuziou J, et al. 2019. Preoperative predictability of right ventricular failure following surgery for Ebstein's anomaly. Eur J Cardiothorac Surg. 55(6):1187-1193.

Postma AV, van Engelen K, van de Meerakker J, et al. 2011. Mutations in the sarcomere gene MYH7 in Ebstein anomaly. Circ Cardiovasc Genet. 4(1):43-50.

Raju V, Dearani JA, Burkhart HM, et al. 2014. Right ventricular unloading for heart failure related to Ebstein malformation. Ann Thorac Surg. 98:167-73; discussion 173-4.

Said SM, Burkhart HM, Schaff HV, et al. 2014. When should a mechanical tricuspid valve replacement be considered? J Thorac Cardiovasc Surg. 148:603-8.
Saxena A, Relan J, Agarwal R, et al. 2019. Indian guidelines for indications and timing of intervention for common congenital heart diseases: Revised and updated consensus statement of the Working group on management of congenital heart diseases. Ann Pediatr Cardiol. 12(3):254-286.

Silva GVRD, Miana LA, Caneo LF, et al. 2019. Early and Long-Term Outcomes of Surgical Treatment of Ebstein's Anomaly. Braz J Cardiovasc Surg. 34(5):511-516. Published Dec 1.

Silva JP, Baumgratz JF, Fonseca Ld, et al. 2004. Anomalia de Ebstein: resultados com a reconstrução cônica da valva tricúspide [Ebstein's anomaly: results of the conic reconstruction of the tricuspid valve]. Arq Bras Cardiol. 82(3):212-216.

Taggart NW, Cabalka AK, Eicken A, et al. 2018. Outcomes of Transcatheter Tricuspid Valve-in-Valve Implantation in Patients With Ebstein Anomaly. Am J Cardiol. 121:262-8. 